\title{
Imagens de Santa Catarina: arte e ciência na obra do artista viajante Louis Choris ${ }^{1}$
}

Luciana Rossato

UFRGS/Capes

\section{RESUMO}

O objetivo deste artigo é analisar as obras que têm como tema a paisagem da ilha de Santa Catarina produzidas pelo artista viajante Louis Choris a partir de sua passagem pela região no ano de 1815. As imagens inserem-se numa longa tradição de produções pictóricas que combinavam arte e conhecimento. As expedições científicas contavam com artistas que tinham a função de reproduzir os espécimes coletados e também as paisagens das regiões visitadas.

Palavras-chave: Choris, L.; Imagem; Ciência.

\section{ABSTRACT}

The purpose of this article is to look into the artwork that has the Santa Catarina island as its main theme produced by the traveling artist Louis Choris from his passage by the region in 1815 . The scientific expeditions had artists whose function was reproducing the specimens collected and also the landscapes of the regions visited. These images insert themselves in a long-time tradition of pictorial productions which mixed art and knowledge.

Keywords: Choris, L.; Image; Science.

Este artigo tem como objetivo analisar as obras que o artista viajante Louis Choris produziu tendo como tema a paisagem brasileira, mais especificamente a ilha de Santa Catarina, localizada ao sul da colônia portuguesa. Entre as inúmeras litografias e desenhos que produziu, encontram-se quatro imagens coloridas, acompanhadas de texto explicativo, publicadas no formato in-fol em 1826 na obra intitulada Vues et paysages des regions équinoxiales recueillis dans un voyage autour $d u$ monde, impressa pela editora Paul Renouard, de Paris. A maioria dos cientistas viajantes utilizava o desenho com o objetivo de acrescentar informações ao que estava sendo relatado nos diários de viagem e os espécimes que estavam sendo coletados. Nos trabalhos dos artistas viajantes acontecia o contrário: era a escrita que acrescentava informações ao que era retratado pelo viajante. 
Louis Choris era desenhista, pintor e litógrafo russo. Nasceu em 22 de março de 1795, em uma família alemã que morava em Iekaterinoslav. Foi enviado para estudar no ginásio de Kharkov, onde seu talento para o desenho aflorou. Seus primeiros ensaios chamaram a atenção do naturalista Marschall de Biberstein que, em 1813, o levou para sua primeira viagem de estudos ao Cáucaso, quando tinha apenas 18 anos. Foi convidado a fazer parte da expedição "Rurick", organizada pelo conde de Romanzov (1754-1826), chanceler do Império Russo, entre os anos de 1815 e 1818. A expedição tinha como meta principal descobrir uma passagem entre o Pacífico e o Atlântico pelo caminho do estreito de Behring. Comandada por Otto von Kotzebue, tal expedição teve grande importância do ponto de vista geográfico, pois permitiu um melhor conhecimento do Pacífico. O "Rurick" visitou sucessivamente Tenerife, a ilha de Santa Catarina, no Brasil, Talcahuanha, na costa do Chile, a ilha de Páscoa, bem como outras ilhas no Pacífico até o estreito de Behring. O trajeto feito pelo navio explorou também a costa da Ásia e a costa oeste da América do Norte. O tempo de permanência na ilha de Santa Catarina foi pequeno, entre o dia 29 de novembro de 1815 e o dia 16 de dezembro do mesmo ano (ou 11 a 28 de dezembro, pelo calendário gregoriano). ${ }^{2}$

Em 1819, um ano após o término da expedição, Choris partiu para Paris, onde conviveu com outros artistas e cientistas. Estudou e trabalhou com Jean Baptiste Regnault e no ateliê de M. Gérard, com os quais aprendeu a técnica da litografia. Em 1827 deixou a França para visitar o México e outras regiões da América. Morreu de forma trágica na cidade de Vera Cruz, México, em 22 de março de 1828, ferido por um golpe de sabre e atingido por uma bala, ao tentar se livrar de assaltantes. Seus trabalhos começaram a ser publicados em Paris a partir do ano de 1819. Além da obra já citada, trabalhos seus podem ser encontrados em Voyage pittoresque autour du monde, accompagné de descriptions de mammifères par M. le baron Cuvier et d'observations sur les crânes humains par M. le docteur Gall, publicado em Paris no ano de 1820, em formato in-fol., com figuras e mapas. Em 1822 surgiu outra edição com o título levemente modificado: Voyage pittoresque autour du monde, avec des portraits de sauvages d'Amérique, d'Ásie, d'Áfrique, et des iles du Grand Ocean; des paysages, des vues maritimes et plusiers objets d'histoire naturelle. Esse trabalho é acompanhado por descrições e observações do Barão Cuvier, de Adalbert von Chamisso e do doutor Gall. Foi impresso pela editora Firmin Didot, de Paris. Essas edições possuíam vários fascículos e eram relativamente caras, por isso muitas somente eram publicadas com a venda antecipada de um número mínimo de exemplares, de maneira que a venda pagasse a impressão 
das gravuras. As pessoas que adquiriam os álbuns, muitas vezes os desmembravam a fim de emoldurá-las.

No Brasil não se encontram traduções completas dessas obras. É possível encontrar partes específicas que foram traduzidas e publicadas em coletâneas, como as quatro pranchas, acompanhadas dos respectivos textos explicativos, publicadas em Ilha de Santa Catarina: relato de viajantes estrangeiros nos séculos XVIII e XIX. Na biblioteca do Instituto de Estudos Brasileiros da USP há uma cópia do Vues et paysages des régions équinoxiales recueillis dans un voyage autour du monde. A Biblioteca Mário de Andrade (SP) possui uma cópia do Voyage pittoresque autour du monde, publicado em Paris no ano de 1822 pela editora Firmin Didot. Além desse material impresso, Afonso d'Escragnolle Taunay cita a existência de uma aquarela que reproduz o cenário da prancha $\mathrm{V}$, com pequenas diferenças no ambiente natural retratado e sem a presença dos bailarinos africanos. Essa obra foi adquirida por Almeida Prado na Europa. ${ }^{3}$

No final do século XVIII e na primeira metade do século XIX a América foi tema de inúmeras imagens, reproduzidas em desenhos, pinturas, xilogravuras, litogravuras etc. Dessa forma, as paisagens e as populações do Novo Mundo tornaram-se acessíveis a um maior número de pessoas na Europa. A litografia, técnica utilizada para reproduzir as imagens de Choris, difundiuse no início do século XIX. O procedimento, que utiliza a pedra para a confecção da matriz, é mais preciso do que a xilogravura. Além de permitir a reprodução em massa, possibilitava a confecção de novas criações.

A utilização de artistas para a produção de imagens sobre regiões pouco conhecidas pelo Velho Mundo remonta ao período das grandes descobertas. Um exemplo são as imagens produzidas por Franz Post que, juntamente com Albert Eckhout, acompanhou o governador holandês Maurício de Nassau durante o período do domínio holandês no Nordeste brasileiro (1630-1654). Inicialmente, a presença desses artistas tinha como objetivo mapear o relevo, os portos e a geografia das novas regiões. Foi somente no final do século XVIII que as missões científicas se multiplicaram, e os artistas que participavam dessas missões passaram a ter outras funções. Continuavam retratando a topografia, mas também dedicavam-se às cidades, aos tipos humanos e aos seus costumes etnográficos. ${ }^{4}$ Marcos Vinicius de Freitas afirma que no período colonial e imperial brasileiro existiram três diferentes influxos no que se refere à pintura e ao desenho de paisagens. O primeiro ocorreu com a vinda de artistas e cientistas da missão de Maurício de Nassau. Franz Post, Albert Eckhout e Georg Marcgraf foram os artistas que, no século XVII, produziram 
imagens sobre o Brasil holandês. Post foi quem estabeleceu a palmeira como um dos símbolos do paisagismo tropical. O segundo influxo localizou-se na primeira metade do século XIX e foi marcado por três eventos: a vinda da Missão Artística Francesa em 1816, a vinda da Missão Científica Austríaca em 1817 e a Expedição Langsdorff, realizada entre os anos de 1822 e 1825 . O terceiro e último influxo foi marcado pela presença do professor Johann Georg Grimm na Academia de Belas Artes, entre os anos de 1882 e 1884. Ele levou seus alunos para fora dos ateliês, para terem contato com a natureza, o que influiria nos padrões acadêmicos da pintura das paisagens. ${ }^{5}$

O trabalho de Louis Choris vinculou-se aos dois primeiros momentos, ou deles recebeu influências. Apesar de não podermos afirmar com certeza se ele teve ou não contato com certos artistas, ou com seus trabalhos, levantaremos algumas considerações. Os trabalhos dos artistas que acompanharam Nassau foram doados a Frederico Guilherme de Brandenburgo. No ano de 1664 foram publicados em Berlim sob o título de Theatrum rerum naturalium brasiliae. A obra compreende 1.460 trabalhos editados em 4 volumes. Em 1814, um estudioso chamado Lichtenstein dedicou vários estudos a essa obra, após localizá-la na Biblioteca de Berlim. Além disso, Maurício de Nassau presenteou o rei da França, Luís XIV, com quatro quadros de Franz Post. Esses trabalhos realizados pelos artistas holandeses ou estavam em Paris, ou estavam sendo objeto de estudo na mesma época em que Choris fazia sua formação de artista viajante, o que aumenta as possibilidades de o jovem tê-los analisado. Além disso, Choris provavelmente teve contato com diversos artistas e cientistas de sua época, uma vez que mantinha relações com Alexander von Humboldt, o qual congregava ao seu redor cientistas, viajantes e artistas, entre eles Rugendas. Artistas e cientistas ou moravam na capital da França, ou então mantinham contato com suas instituições, como por exemplo o Muséum National d'Histoire Naturelle. Um ano após o término da viagem no "Rurick" (1815-1818), Choris mudou-se para Paris, e permaneceu na cidade até o ano de 1827, quando deixou a França rumo ao México, onde veio a falecer.

As imagens que têm como motivo a América podem ser divididas em dois tipos. Uma das formas mais freqüentes era a pintura de vistas sobre as cidades da América Colonial, onde podemos perceber a preocupação dos artistas em registrar o entorno das vilas e seu aspecto geral, inserindo ou não os indivíduos que viviam no local. A outra forma consistia na produção de imagens da natureza, fosse ela no seu conjunto, como o pregado por Alexander von Humboldt, fosse ela compartimentada, com animais ou plantas sendo pintadas individualmente, em detalhes. No primeiro tipo de imagem, $o$ 
interesse estava voltado para o que o homem produziu, principalmente as cidades. No outro, o olhar se voltava para a natureza, em decorrência principalmente do desenvolvimento das ciências naturais.

As cidades da América eram pintadas inicialmente vistas de cima e paulatinamente passaram a ser retratadas de frente e em detalhes, num movimento contrário às vistas das cidades européias, sempre retratadas de frente e posteriormente vistas de cima. As cidades retratadas de cima, ${ }^{6}$ de forma perspectivada, nos mapas em escala reduzida, substituíram as representações de perfil e/ou idealizadas do início da ocupação da América pelos europeus. Posteriormente, os viajantes passaram a retratar as cidades de frente, a partir do mar, nos conhecidos perfis urbanos. Retrataram os morros e as construções, normalmente capelas, igrejas e construções militares. ${ }^{7} \mathrm{O}$ interesse europeu em retratar as cidades surgiu no século XV, relacionado com a expansão comercial, a secularização da arte e o progresso da imprensa. As primeiras vistas das cidades surgiram nos Atlas, onde arte e geografia estavam unidas. No século XVI a produção de vistas e mapas foi ampliada. As cidades eram representadas do ponto de vista de um pássaro (vôo-de-pássaro ou vol d'oiseau), numa tomada globalizante do espaço. Além disso, os mapas eram decorados com produtos da cidade retratada, chamando a atenção para suas riquezas.

Nas pinturas do Nordeste brasileiro, produzidas por artistas holandeses durante o governo de Nassau, são identificados produtos tropicais, como frutas e animais. Esse tipo de produto, vistas de regiões distantes como a Ásia e a África, tornou-se sucesso na Europa entre os anos de 1785 e 1860. As vistas que tinham a América como tema começaram a ser publicadas no início do século XIX. Valéria Salgueiro salienta que

sendo o álbum de vistas urbanas produzidas pelos viajantes europeus expressão ao mesmo tempo da cultura latino-americana (quanto ao objeto retratado: a cidade) e da cultura européia (quanto à natureza do produto: o álbum ilustrado de vistas), sua história não pode estar divorciada da história mais ampla das vistas urbanas da própria Europa, já que estas compõem sua matriz de origem. ${ }^{8}$

Em razão dos interesses marítimos e comerciais, que se somaram à propagação de um conhecimento científico baseado na História Natural, difundiu-se a preocupação de registrar de forma a mais fidedigna possível as regiões não-européias. Além desses interesses, devemos salientar o aumento na procura e difusão de vistas e pinturas por uma crescente classe média letrada, 
que utilizava as reproduções na decoração de suas residências. Somou-se a isso a difusão do mercado editorial, conseqüência do maior poder aquisitivo e do aprimoramento técnico, que possibilitava produzir em larga escala gravuras baseadas nas pinturas e aquarelas feitas pelos artistas viajantes, vendidas como álbuns ilustrados.

Madeleine Pinault classifica as obras dedicadas à História Natural em duas categorias: a tendência pitoresca e as coleções iconográficas sobre pergaminho. A tendência pitoresca refere-se à pintura com sujeitos diversos, destinada aos gabinetes ou à decoração de construções reais. Essas obras reproduziam imagens de plantas, animais e paisagens, que eram do interesse dos colecionadores, normalmente feitas por artistas renomados que recriavam a ilusão de natureza. Já as coleções iconográficas sobre pergaminho permitiam que as espécies animais e vegetais fossem classificadas e preservadas por meio da imagem. Além disso, a difusão desse conhecimento científico seria ampliada, principalmente entre os amadores. Outro aspecto que a autora salienta é a utilização econômica desse tipo de produção iconográfica. Muitos dos desenhos eram utilizados para o estudo da História Natural e da anatomia, mas outros eram destinados às manufaturas de tecidos e porcelanas, sendo reproduzidos pelos artesãos. A natureza oferecia inúmeras possibilidades, pois seus temas poderiam ser utilizados nas artes e também nos ofícios. ${ }^{9}$

Os artistas viajantes que trabalhavam em expedições científicas tinham a função de produzir um material a ser utilizado como material de pesquisa e estudo, principalmente quando o tema era científico-natural - por exemplo, desenhos da flora e da fauna. Com a expansão do conhecimento científico nos séculos XVII e XVIII houve um estreitamento da relação entre o artista e o cientista na busca de uma representação mais exata e confiável do objeto, fosse ele uma cidade ou aspectos da natureza. Nesse período, graças à expansão da ciência, a arte gráfica passou a ser utilizada como ilustração do conhecimento. Criou-se uma tensão entre o gosto estético e a demanda por um trabalho que tivesse a preocupação com a exatidão das formas e das cores, já que essas imagens seriam utilizadas para a difusão do conhecimento científico. Além disso, difundia-se na Europa uma estética que valorizava o passado, as paisagens naturais, cultivando-se o gosto pelo pitoresco e pelo sublime numa visão estetizada da natureza, no momento em que na Europa a paisagem estava sendo profundamente transformada por causa da Revolução Industrial. ${ }^{10}$

É nesse contexto que se difundiu o gosto pelos álbuns e pelos livros de viagens ilustrados, principalmente de paisagens. A natureza passou a ser valorizada por si mesma, ela era a artista. Mas essas paisagens exóticas eram re- 
tratadas a partir de lugares-comuns, ${ }^{11}$ o que fazia que a natureza de lugares distantes fosse ajustada ao gosto europeu, tornando-se assimilável ao público a quem eram destinadas. Entre as pinturas, cujo motivo era a natureza, podemos perceber dois tipos de representação, influenciados respectivamente por Conrad Gessner e por Alexander von Humboldt.

Conrad Gessner (1516-1565), naturalista e desenhista de talento, produziu no final da vida um estudo sobre dois tipos de Íris, a Íris Gramínea e a Íris da Sibéria (Figura 1). A última foi desenhada em detalhes, com anotações explicativas. Sua obra marcou uma ruptura entre uma ilustração botânica puramente artística - em que flores, frutos e animais faziam parte do cenário ou então compunham uma natureza-morta - e encaminhou-se para um estudo das plantas, descrevendo-as cientificamente, pressagiando desta forma as futuras pesquisas dos cientistas.

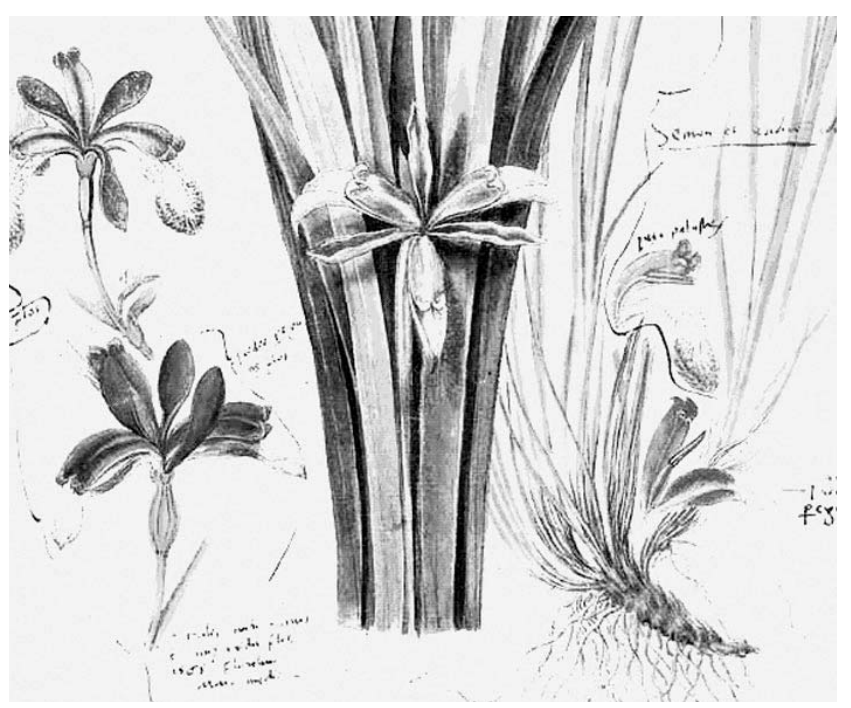

Figura 1: Iris Graminea - Conrad Gessner, 1643. Historia Plantarum. In: www.amo-bulbi.it/tav_Iris_Gec.htm, acesso em: 10.01.2005 (detalhe).

Essa forma de retratar a natureza foi ao encontro da teoria científica de Carl von Linné, difundida na primeira metade do século XVIII. No modelo de representação artística influenciada por Linné, o conhecimento era compartimentado e ordenado. O fundamento da ciência clássica era o desenho matemático e o sentido da visão. O melhor exemplo desse gênero de arte eram as reproduções de espécies vegetais (Figura 2). Essas eram recortadas e pintadas em seus detalhes, a partir de vários ângulos, ou seja, individualizadas e posteriormente comparadas e classificadas pelas regras estabelecidas pela História Natural.

Por sua vez, a concepção artística difundida por Humboldt enfatizava uma visão pictórica que tinha a intenção de abraçar o todo, considerando as diversas formas de vida como interdependentes. Ele solicitava aos artistas que, 


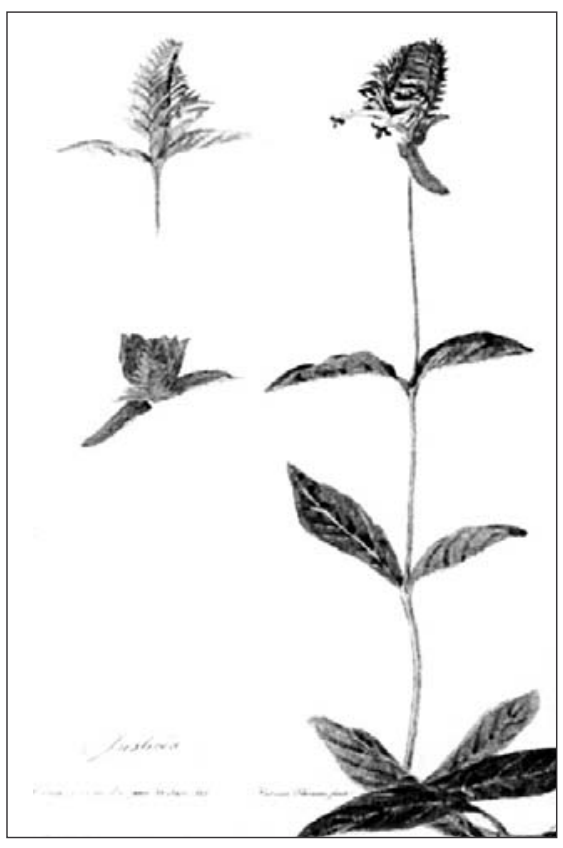

Figura 2: Lophostachys publiflora lindau - Hercule Florence, 1828. In: Expedição Langsdorff ao Brasil 1821-1829. Iconografia do Arquivo da Academia de Ciências da União Soviética. Rio de Janeiro: Alumbramento/Livroarte, 1988, v.3, p.21.

em seu trabalho de representar a natureza, não utilizassem as espécies trazidas das viagens nem as que se encontravam nas estufas, o que fatalmente remeteria a uma reprodução das plantas deslocadas de seu ambiente de origem. Para ele, as plantas deveriam ser representadas em seu ambiente natural, no que denominava de "o grande teatro da natureza tropical". Os interesses de Humboldt estavam voltados para o estudo das relações entre os seres humanos e a natureza e como elas contribuem para a formação da paisagem. Em sua obra Cosmos, a paisagem é entendida como a "representação mental de um espaço real cujo conteúdo é, por excelência, diversificado". ${ }^{12}$ A geografia, enquanto área do conhecimento, aprofundou algumas discussões em torno do tema. Esse interesse deveu-se ao fato de que o conceito de paisagem, de natureza e de cultura eram temas caros à sociedade e polêmicos para os estudiosos da área. As dificuldades em analisar as representações sobre as relações dos homens entre si e destes com a natureza foi um dos aspectos que contribuiu para a polêmica entre os estudiosos da geografia. Para Carl O. Sauer, a paisagem, apesar de sua individualidade, estabelecia relações com outras paisagens. Além disso, seu processo de modelagem não era somente físico. Uma área era composta por uma associação distinta de formas que eram físicas e culturais. ${ }^{13}$ Além da questão cultural, Edvânia Gomes acrescenta outro aspecto, que se refere aos valores atribuídos histórica e culturalmente aos elementos da natureza. São esses valores que determinam suas posições hierárquicas. A paisagem constitui-se como uma representação e reapresentação do mundo, uma vez que "resulta da apreensão do olhar do indivíduo, que, por 
sua vez, é condicionado por filtros fisiológicos, psicológicos e econômicos, e da esfera da rememoração e da lembrança recorrente". ${ }^{14}$ Essas discussões podem ser remetidas para a análise da representação plástica da natureza, de suas formas idealizadas. Além da evocação do conteúdo, busca-se também capturar seu caráter "natural". Nessas imagens a natureza pode ser apresentada como uma instância selvagem mas também como bucólica, nostálgica, remetendo à idéia de harmonia.

Nas litogravuras referentes à ilha de Santa Catarina, elaboradas por Louis Choris, a partir de sua passagem por estas paragens no ano de 1815, podemos perceber a influência de Humboldt. O álbum no qual elas foram publicadas, Vues et paysages des régions équinoxiales..., foi dedicado a ele. As litografias foram produzidas durante sua estada em Paris, após a viagem, e publicadas no ano de 1826. Como artista contratado, muitos dos trabalhos produzidos durante a viagem provavelmente foram desenhos voltados para os estudos científicos e pertenciam aos órgãos que organizaram e financiaram a viagem. Infelizmente não tivemos acesso a esses trabalhos. As imagens que fazem parte do álbum devem ter sido feitas após seu retorno à Europa, com base em esboços. Na obra que estamos utilizando para este estudo estão reproduzidas quatro pranchas referentes ao Brasil, mais especificamente à ilha de Santa Catarina, uma vez que a expedição da qual Choris participava não parou em outras regiões do Reino Português. O porto do Rio de Janeiro foi evitado por causa do medo de doenças, comuns em razão da insalubridade da cidade.

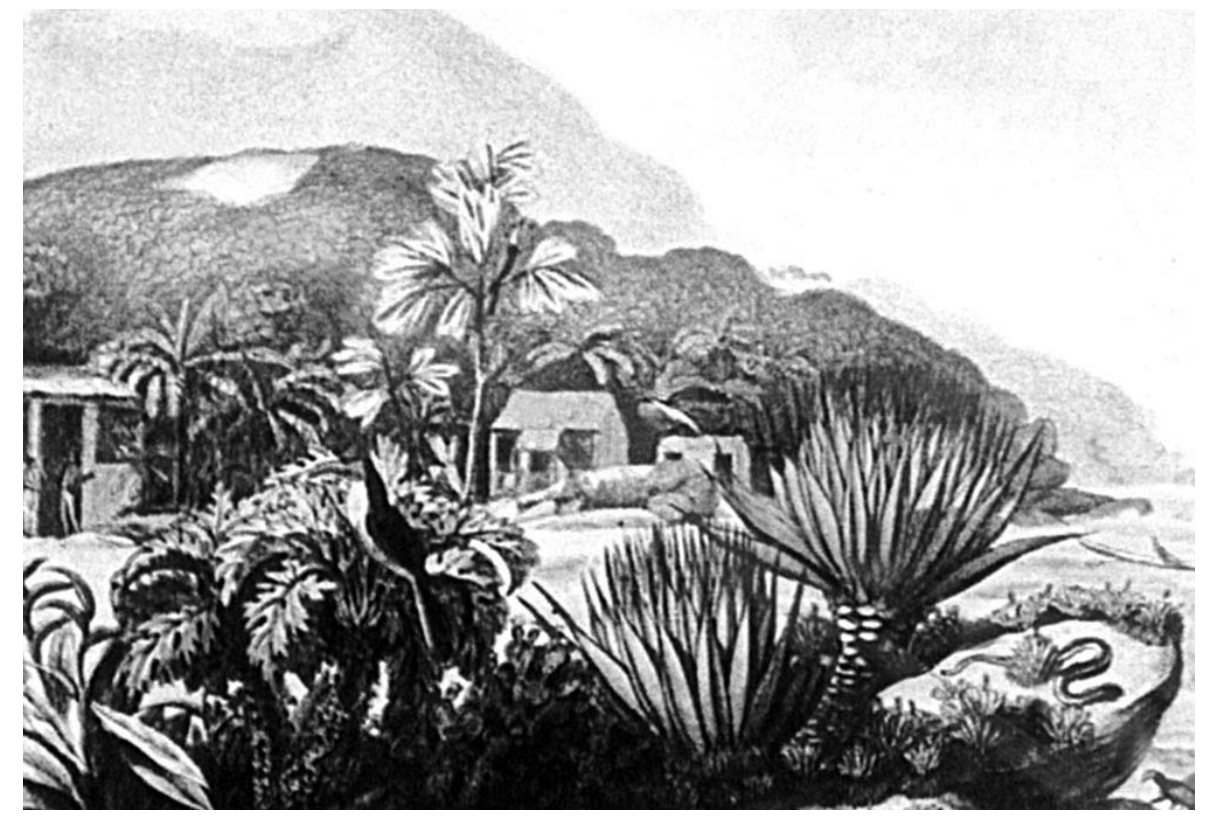

Figura 3: Brèsil - desenho de Louis Choris - $(20,7 \mathrm{~cm}$ x $26 \mathrm{~cm})$. In: CHORIS, L. Vues et paysages de regions équinoxiales recueillis dans un Voyage autour du monde. Paris: Paul Renourd, 1826. Prancha II. 
A primeira coisa que chama a atenção nas pranchas é o espaço ocupado pela natureza. Ela é representada grande e exuberante, enquanto os seres humanos e sua produção cultural, como por exemplo as casas, aparecem de forma marginal, em segundo plano, apesar de algumas vezes centralizados. Isso ocorre nas pranchas II e IV. ${ }^{15} \mathrm{Na}$ prancha III (Figura 3) a moradia ocupa um plano intermediário, localizado no lado direto, "sombreada por laranjeiras e bananeiras". Já o indivíduo que é reproduzido enquanto trabalha, carregando cachos de bananas, está localizado no primeiro plano, mas sua imagem quase passa despercebida diante da grandeza dos espécimes vegetais aí retratados, neste caso duas espécies de cactos, o "opúncia" e o "colossal”, e pés de "ananases". Nos textos explicativos que acompanham as pranchas, Choris afirmou que, em suas andanças pelo interior da ilha, "fica-se tomado de admiração vendo-se a variedade, a força e as dimensões gigantescas dos vegetais que, num espaço bastante restrito, recobrem o solo". ${ }^{16}$ A riqueza e a variedade de espécies vegetais encontradas na flora tropical encantava e surpreendia os viajantes, fossem eles cientistas ou não.

As mudanças científicas que ocorreram na segunda metade do século XVIII iriam influenciar também a sensibilidade dos artistas em relação à natureza. A partir desse momento os cientistas saíram dos gabinetes onde estavam encerrados, estudando as espécies deslocadas de seu contexto natural, e passaram a percorrer o mundo, acompanhados de desenhistas e artistas a fim de estudar a natureza ao ar livre. Ao mesmo tempo em que estavam interessados em descobrir, estudar e analisar a natureza, dedicavam-se também às questões históricas, geográficas e etnológicas das regiões visitadas. Além das transformações científicas, escritores e poetas como Jean-Jacques Rousseau e Salomon Gessner ${ }^{17}$ também tiveram um papel importante na formação do gosto dos artistas e dos amadores por paisagens e fenômenos naturais. ${ }^{18}$

Na prancha II (Figura 4), a primeira que retrata as regiões tropicais, nomeada como "Brèsil", as cores e a exuberância da natureza estão colocadas em primeiro plano. Helicônias, philodendrum (popularmente conhecida como costela-de-adão), cactos, bromélias e outras plantas são pintadas ao lado de alguns animais, como o tucano. Apesar de não ser possível identificar as espécies botânicas, somente as famílias, e na reprodução do tucano constatarmos imprecisões na pintura da plumagem, Choris compôs uma imagem dessa região da América que vai ao encontro das representações que se tinha dos trópicos: plantas e animais coloridos, natureza exuberante e exótica e a presença reduzida do ser humano.

No século XVIII, e principalmente na primeira década do século XIX, 


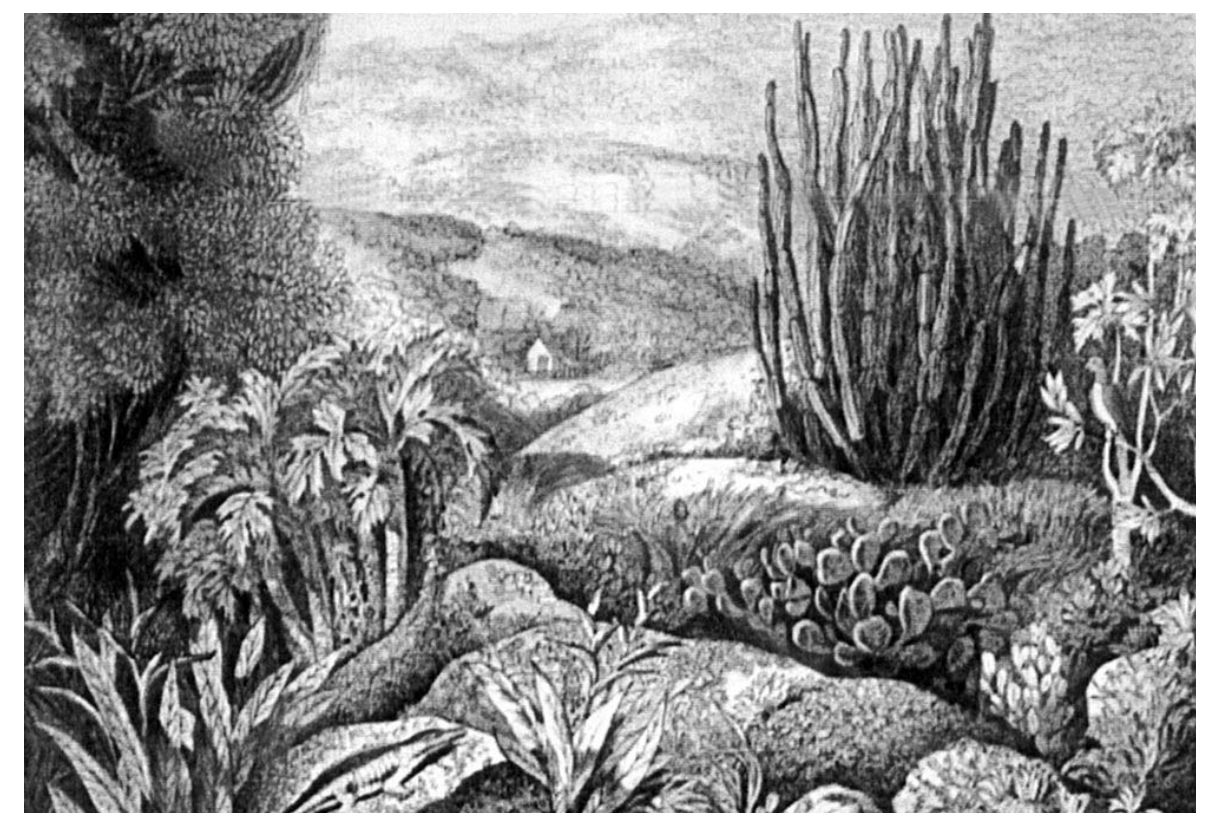

Figura 4: Vue dans l'interieur de l'Ile de Ste Catherine (Brèsil) - desenho de Louis Choris - $(21 \mathrm{~cm} \times 26,6 \mathrm{~cm})$ In: CHORIS, L. Vues et paysages de regions équinoxiales recueillis dans un Voyage autour du monde. Paris: Paul Renourd, 1826. Prancha III.

desenvolveram-se na História Natural estudos do que mais tarde seria chamado de biogeografia, paralelamente à classificação. Humboldt, que viajou pela América Espanhola, desenvolveu estudos sobre a geografia das plantas que influenciaram seus contemporâneos. De suas conclusões, dois aspectos nos interessam particularmente. Um é o entendimento de que os seres vivos só podiam ser compreendidos quando relacionados com os lugares onde se desenvolveram e com os outros seres vivos com os quais estavam relacionados. O outro aspecto refere-se às impressões estéticas experimentadas pelo viajante em cada região por onde passava. Para ele, essas impressões eram parte integrante do trabalho científico, e não podiam ser substituídas por estudos de amostras ou descrições feitas em gabinetes. Essas concepções de Humboldt é que iriam contribuir para justificar a utilização de artistas viajantes nas expedições.

A arte vinculava-se estreitamente ao trabalho científico. Exemplos dessa vinculação podem ser encontrados em várias expedições, mesmo entre as que transitaram pelo Brasil e contaram com artistas tais como Johann Moritz Rugendas, Hercule Florence e Thomas Ender. ${ }^{19}$ Podemos perceber que, em seus trabalhos, Choris seguiu as recomendações feitas por Humboldt. Os esboços, e mesmo alguma pintura mais elaborada, eram feitos tendo a natureza como modelo. O trabalho de reprodução em litografia foi elaborado posteriormente, 
quando já se encontrava na Europa, mas tendo como base os inúmeros trabalhos realizados durante a viagem. Além de pintor e viajante, Choris também era litógrafo, o que contribuiu para a qualidade de suas gravuras, uma vez que ele conhecia as possibilidades de reprodução de seus esboços.

Além do contato direto com a natureza que seria o objeto de estudo, Humboldt também estabeleceu o que se denominou o estudo das "fisionomias das paisagens". Segundo ele, existiam vegetais sociais e vegetais associais. As plantas que compunham a natureza tropical eram do grupo associal, ou seja, conviviam espécies de tipos diferentes entre si. E era esse um dos aspectos que impressionava os viajantes europeus, acostumados com os bosques de seu continente, que reuniam várias plantas das mesmas espécies, como pinheiros e carvalhos. O grande número de espécies diferentes convivendo juntas, entrelaçando seus galhos e constituindo um colorido composto por vários tons de verde, era um espetáculo que os impressionava. A natureza tropical, com seu colorido exuberante nas flores e nos pássaros, também foi reproduzida por Choris. A fisionomia da paisagem dos trópicos era composta por algumas espécies básicas, encontradas em suas obras. Temos a presença de coqueiros, cactos, bananeiras, bromélias e helicônias entre as plantas, e de pássaros coloridos como os tucanos e as araras azuis. Os pássaros típicos dos trópicos são vistos nas gravuras II, III e IV (Figura 5). No caso do pássaro azul e amarelo, sua reprodução não corresponde a nenhum tipo de pássaro conhe-

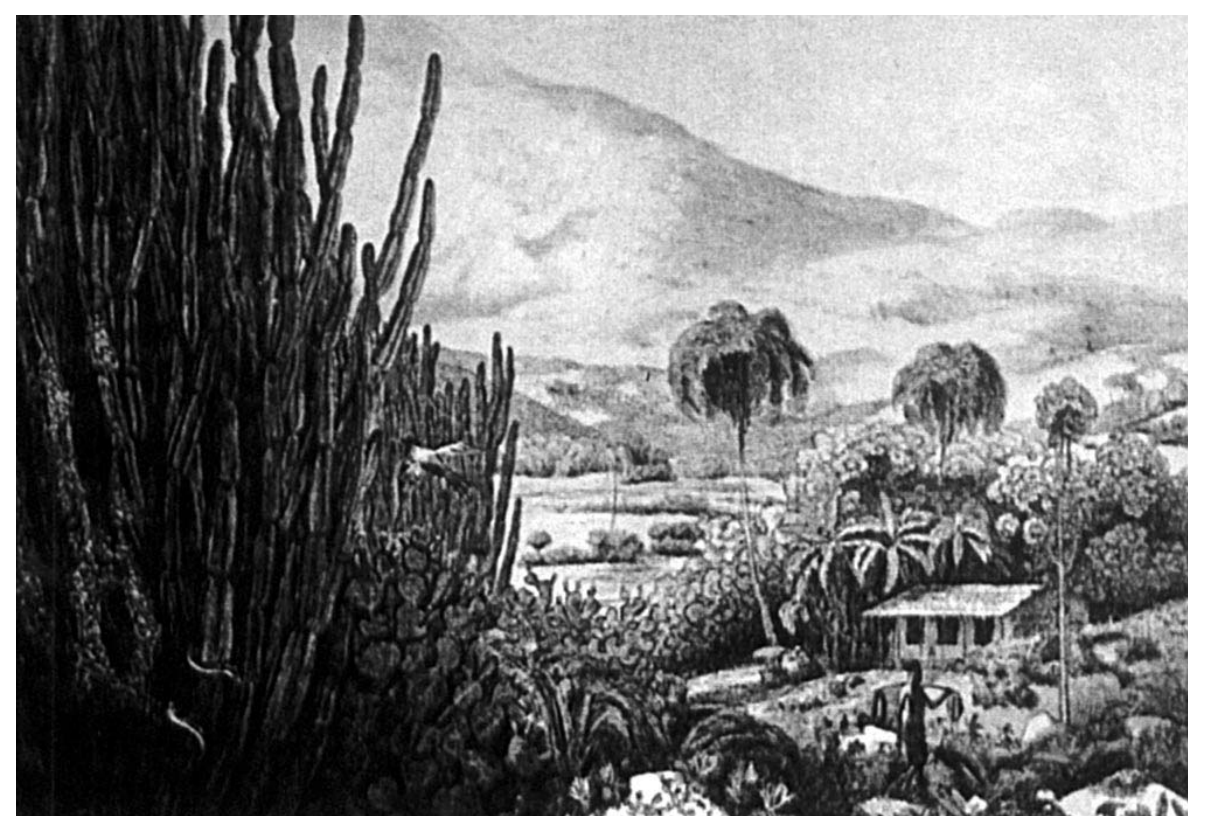

Figura 5: Ile de St ${ }^{e}$ Catherine (Brèsil) — desenho de Louis Choris — $(21,8 \mathrm{~cm} \mathrm{x} \mathrm{26,8} \mathrm{cm)}$

In: CHORIS, L. Vues et paysages de regions équinoxiales recueillis dans un Voyage autour du monde. Paris: Paul Renourd, 1826. Prancha IV. 
cido. A certeza de que o animal por ele desenhado é uma arara surge apenas ao lermos o texto que acompanha todas as imagens. Segundo João de Deus Medeiros, professor de botânica da Universidade Federal de Santa Catarina, as quatro pranchas reproduzidas nesse álbum não são úteis para os estudos de taxonomia. Tal fato não ocorre com os desenhos de plantas feitos pelo viajante Martius, que ainda são utilizados nos estudos de botânica. Isso se explica porque esses desenhos seguiam os preceitos indicados por Linné, como os feitos por Hercules Florence (ver Figura 4). Entretanto, as imagens de Choris são úteis para identificar a paisagem e as transformações causadas pela ocupação humana. Nas obras de Spix e Martius também são encontradas imagens de paisagens, como a intitulada "Lagoa de aves à margem do rio São Francisco". Como nas pranchas de Choris, essas paisagens eram acompanhadas por textos explicativos que citavam as plantas e os animais retratados.

Na prancha V (Figura 6) a natureza está presente em toda sua grandiosidade, através de altas árvores, como o coqueiro e o mamoeiro, e de outras espécies como as bananeiras, os cactos e os ananases. Ao fundo aparecem os morros e, à direita, a praia e o mar. O que diferencia essa prancha das outras é a presença de cenas de costumbrismo, que são descrições da vida popular. Em todas as pranchas são reproduzidos indivíduos ou então moradias, mas nessa o tema central desloca-se da natureza para o ser humano. Um grupo posicionado em roda, à sombra de uma jabuticabeira, no qual um indivíduo

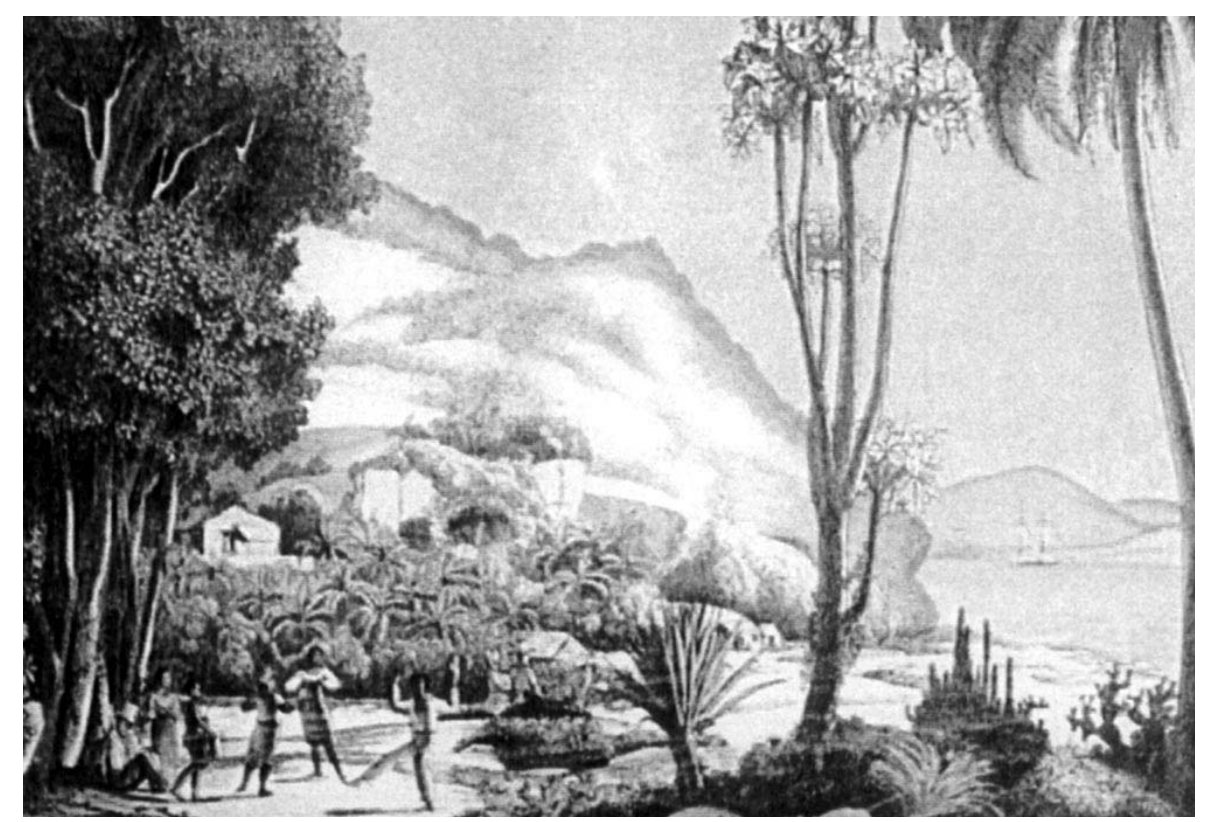

Figura 6: Vue de la cöte du Brèsil vis à vis de l'Ile de St $t^{e}$ Catherine (Brèsil) — desenho de Louis Choris - (20,9 cm x 26,3 cm) In: CHORIS, L. Vues et paysages de regions équinoxiales recueillis dans un Voyage autour du monde. Paris: Paul Renourd, 1826. Prancha V. 
dança e toca um pandeiro, enquanto outro toca um tamborim, mulheres dançam e outros dois encontram-se fora da roda, observando. Segundo Choris, "pelo fim do dia os negros, para se distraírem de seus trabalhos penosos, reúnem-se e dançam: por toda parte onde esta raça de gente habita, ela se entrega com paixão a esse divertimento". ${ }^{20}$

No momento podemos levantar dois aspectos. Primeiramente o fato de que, como outros viajantes, Choris utilizava o termo "negros", sem fazer distinção se estes eram livres ou escravos. O outro aspecto foi sua generalização, dizendo que a dança era um divertimento ao qual se entregavam os indivíduos de toda uma "raça". Seria essa uma conclusão inconseqüente, já que Choris não conhecia tantas regiões onde a presença negra era freqüente, ou ela se baseava em leituras prévias de outros viajantes? Georg von Langsdorff, no relato que trata de sua passagem pela ilha de Santa Catarina, no final de 1803 e início de 1804, dedicou um grande espaço à descrição das danças dos negros e de sua música, que ele considerava um barulho ensurdecedor. Um dos itens na preparação de um viajante era a leitura de outros relatos, que haviam sido publicados na Europa. Além disso, muitos dos viajantes trocavam correspondências entre si, ou mesmo eram amigos ou colegas nas Academias de Ciência e Museus de História Natural. Essas questões nos remetem à representação sobre a América, sua natureza e seus habitantes que circulavam pela Europa, e que iriam direcionar o olhar do viajante, fosse este um marinheiro, um cientista ou um artista.

Voltando à análise da prancha $\mathrm{V}$, num segundo plano, quase encoberto pelas plantas, encontra-se um casal de descendentes de europeus, provavelmente proprietário de terras, trajado com apuro. O texto explicativo não se refere a eles, como também não comenta sobre o barco representado à direita da imagem. Fala rapidamente sobre as habitações humanas, descrevendo-as como "sítios que a imaginação mais brilhante não poderia crê-las mais agradáveis do que elas são na verdade". ${ }^{21}$ Em resumo, compõe um quadro pitoresco, formado por casas envoltas por uma vegetação exuberante, com muitas árvores frutíferas, como bananeiras e mamoeiros e, mais afastadas, plantações de milho. Apesar de escrever nesse texto que a dança era uma distração após o trabalho penoso do dia, o que Choris salienta na pintura são grupos de indivíduos desocupados, reforçando assim o estereótipo sobre os habitantes locais.

Um outro tipo de pintura produzida pelos artistas viajantes eram as vistas de cidades, como, por exemplo, a "Vista da vila de Desterro a partir do Hospital” 22 (Figura 7), pintada por Jean Baptiste Debret. Esse artista não acom- 


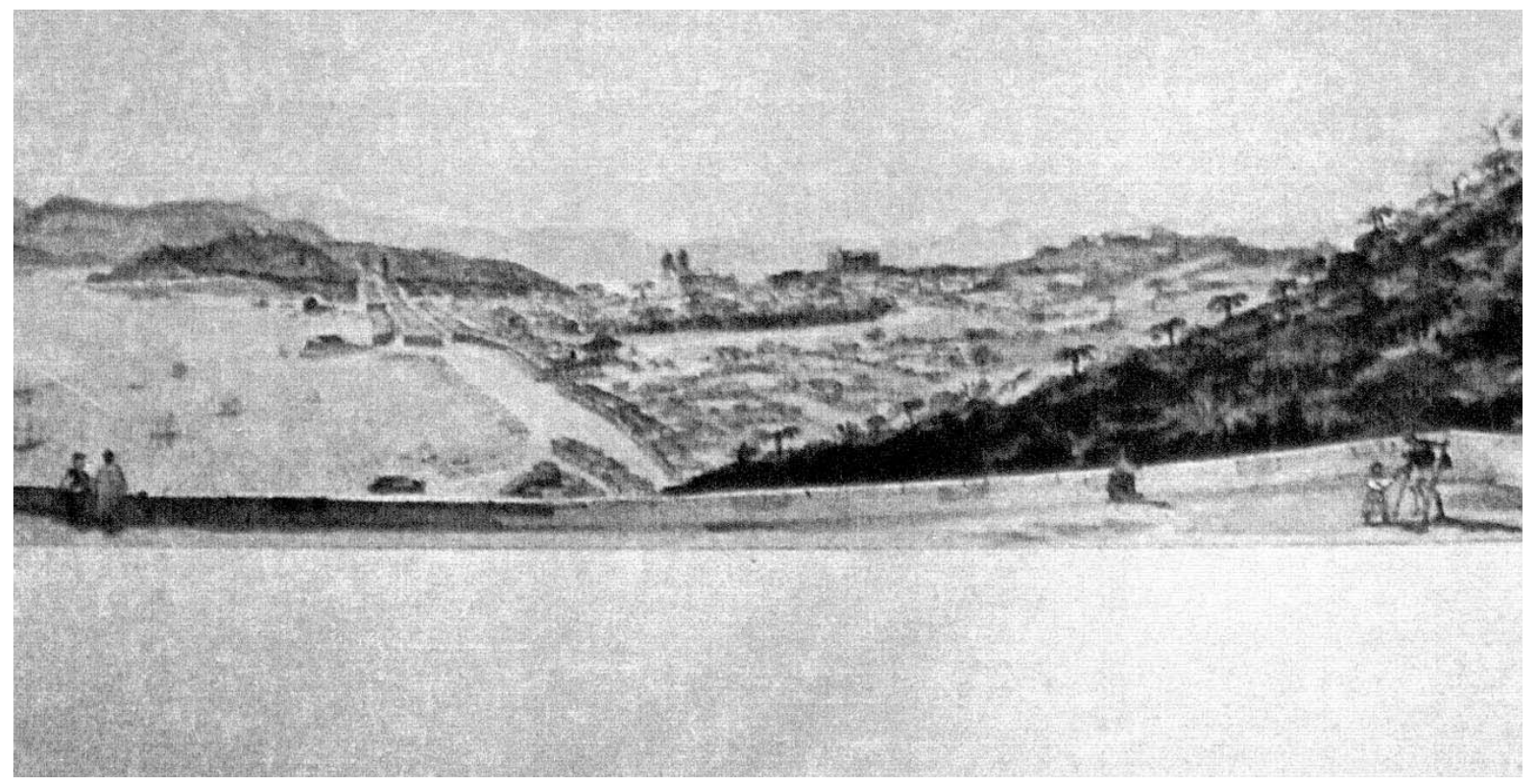

Figura 7: Vista da vila de Desterro a partir do Hospital — Aquarela de Jean Baptiste Debret -

(37 cm x 10,5 cm) In: DEBRET, J. B. Viagem pitoresca e histórica ao Brasil. Paris:

R. de Castro Maya, 1954. Prancha 70 — Laguna (nomeado incorretamente).

panhava uma expedição científica, tal qual Louis Choris, e suas obras tinham outras finalidades, o que influenciou em sua produção final. Nosso interesse nessa obra justifica-se pela possibilidade de trabalharmos comparando dois tipos de imagens que tomaram como referência a mesma região. Ambos eram indivíduos europeus, tinham a mesma profissão e produziram essas imagens em períodos relativamente próximos, ${ }^{23}$ mas, no entanto, o resultado que emergiu de seus pincéis é distinto, apesar de possuírem alguns pontos em comum. Enquanto para Debret o central é a vila e o homem que nela habita, para Choris é a natureza. Segundo ele, o homem e o resultado de sua cultura tornamse periféricos diante da grandeza de uma "natureza ainda selvagem". ${ }^{24}$

As vistas eram feitas a partir de um ponto alto e com um ângulo aberto, buscando dessa forma representar uma visão geral da cidade e de seu entorno. Nessa obra, pintada na primeira metade do século XIX, podemos perceber que não existia uma preocupação em detalhar as construções. Salientavam-se os prédios maiores, como por exemplo a Igreja Matriz, mas o ponto de observação distante impedia que outras construções menores fossem percebidas em sua individualidade. O olhar era de longe, sem perceber as particularidades da cidade, de suas construções e de seus habitantes. Uma metáfora da visão dos viajantes em relação à América. O retratado era o que, de certa forma, já fazia parte da imagem européia da região. Uma paisagem idílica, onde a maior parte era tomada pela natureza, tão grandiosa que o trabalho do ser humano, no caso a cidade, ocupava um espaço reduzido. 
O ponto de observação do pintor é o pátio do hospital, atual Hospital de Caridade, localizado no morro denominado Boa Vista. No primeiro plano podemos perceber alguns temas comuns, que são retratados em vistas de outras cidades brasileiras: dois negros carregando um doente, um indivíduo caminhando com a ajuda de muletas e na companhia de uma criança, e outros indivíduos, que pelas roupas parecem ser religiosos. Debret fazia parte de uma expedição artística financiada pelo governo português, e esteve no Brasil com o objetivo de ministrar aulas na Escola de Belas Artes (que não teve um prédio próprio durante sua permanência no país). Pintou muitas obras a pedido do governo - inicialmente o português, e mais tarde o do Império do Brasil, após a Independência - e também muitas cenas urbanas, nas quais retratou o trabalho e o cotidiano de vida dos escravos. Após sua mudança para o Brasil, mudou o estilo e os temas de suas pinturas, influenciado pela experiência e pelo contato com a sociedade colonial. Apesar de ter se dedicado a diversos temas, também foi influenciado pelos interesses do mercado consumidor, neste caso, o europeu. No início do século XIX, vistas de cidades estavam na moda, e Debret reproduziu várias delas, de diferentes cidades, como Laguna, São Paulo, Santos e São Vicente, entre outras. Na vista de Desterro, podemos constatar o gosto pelo diferente, pelo pitoresco. Grande parte da pintura é tomada pelo tema da natureza: a vegetação, onde podemos constatar a presença de coqueiros, os suaves contornos dos morros ao fundo e o mar. O interesse pelo "exótico", pelo "tropical", pelo "pitoresco" continua presente, mesmo com o desenvolvimento de um olhar classificador e científico sobre a América e as regiões tropicais.

Mesmo os artistas que, como Debret, não pintavam com o objetivo de produzir um material complementar ao trabalho científico, eram influenciados pelos métodos utilizados pelos cientistas para a observação de um país e uma cultura estranha. Na obra que estamos analisando, Debret preocupouse em retratar a mata e nela incluir as palmeiras, um dos tipos básicos da natureza do Brasil. No entanto, essa natureza é a moldura para a vila, para o que o homem havia produzido. Em outras obras suas, que retratam os escravos no Rio de Janeiro, também incluiu aspectos da natureza local, como na prancha em que retrata os ajudantes dos naturalistas, ou então os negros de ganho vendendo frutas típicas na cidade do Rio de Janeiro. Mas, apesar de sofrer influências e retratar aspectos que interessavam aos estudiosos, seu objetivo era distinto. Segundo Ana Belluzzo 
a atenção de Debret não se dirige para construção da idéia de natureza, nem para o reconhecimento das riquezas naturais, nem de uma humanidade em estado natural. Debret trata de centrar a atenção no estado geral da sociedade, buscando apreendê-la com base no entendimento da transformação da natureza em cultura, do natural em civilizado. A concepção procede da Ilustração francesa, acrescida do interesse pelas particularidades dos povos. ${ }^{25}$

Jean Baptiste Debret nasceu em Paris no dia 18 de abril de 1768, filho de um escrivão do Parlamento de Paris. Seu pai tinha parentesco com o arquiteto Demaison e com os pintores François Boucher e Louis David. Após os estudos básicos, aprofundou-se no conhecimento do desenho e da pintura na escola do célebre pintor Louis David, tendo até mesmo acompanhando o mestre em uma viagem de estudos à Itália. Retornou no ano de 1785 a Paris e apresentou trabalhos na Escola da Academia de Paris. Com a vitória no Salão de 1798, tornou-se conhecido, aumentando os convites para executar trabalhos, como pinturas e decorações em casas particulares, cujos temas versavam sobre a História Antiga e fatos militares. Recebeu várias encomendas do governo francês e, em 1815, após a morte de seu único filho de 19 anos, resolveu aceitar o convite de Lebreton, o qual estava organizando a Expedição Artística Francesa a pedido do Marquês de Marialva. Aos 47 anos embarcou em uma viagem para o Brasil, chegando ao Rio de Janeiro em 25 de março de 1816, onde viveu e montou seu ateliê, numa casa no bairro do Catumbi. Permaneceu no país por 15 anos, com a atribuição de desenhar e pintar cenas oficiais e produzir retratos da nobreza, sendo um dos responsáveis pela construção da imagem e da simbologia do Governo Imperial Brasileiro. No Brasil abandonou os cânones do neoclassicismo, procurando adequá-lo ao novo cenário. A partir de 1821, passou a registrar aspectos das cidades, principalmente do Rio de Janeiro, desenhos da paisagem e de costumes locais, como as festas religiosas, a relação entre senhores e escravos e os usos e costumes do país. Teve vários discípulos, apesar dos contratempos sofridos pela Escola de Belas Artes. Entre os anos de 1826 e 1830 realizou diversas exposições. Retornou a Paris em 25 de julho de 1831, onde veio a falecer no ano de 1849, aos 80 anos de idade. ${ }^{26}$

Para trabalharmos com essas pinturas existe a necessidade de definirmos o que é iconografia, um termo muito utilizado pelos estudiosos para definir as imagens produzidas pelos artistas, fossem estes viajantes ou não. Erwin Panofsky define iconografia a partir do termo 'grafia', que vem do grego grafhein e significa escrever. Para ele, iconografia "é a descrição e classificação das ima- 
gens", sendo um "ramo da história da arte que trata do tema ou mensagem das obras de arte em contraposição à sua forma". ${ }^{27}$ Essa área de estudo possui seus limites, uma vez que ela fornece os dados e informações imprescindíveis para a análise, mas não faz as interpretações. Essa é realizada pela iconologia, que é um método de interpretação dos valores simbólicos que estão vinculados à época em que determinada obra foi produzida. ${ }^{28}$

As definições de Panofsky nos remetem às discussões de E. H. Gombrich, quando este salienta a importância dos lugares-comuns e também do poder das convenções e das tradições de determinada época e cultura sobre a forma que as obras assumem. Segundo Gombrich, "toda representação se funda em convenções". ${ }^{29}$ Devemos salientar que as imagens servem de suporte às representações. No nosso entendimento, não podemos utilizar as imagens produzidas pelos viajantes como registros do real, mas sim como uma construção discursiva que foi influenciada pela cultura na qual esses artistas viajantes estavam inseridos, bem como pelas convenções estéticas e pelas possibilidades técnicas disponíveis na época. Isso não significa dizer que essas obras não podem ser utilizadas como fontes, mas sim que elas não podem ser tomadas como o real, como uma imagem fidedigna que possui um caráter comprobatório. Outro ponto para o qual gostaríamos de chamar a atenção é que todos os documentos devem ser inseridos e problematizados no seu contexto de produção, e isto também se aplica às imagens produzidas pelos artistas viajantes. ${ }^{30}$

Ao analisarmos uma imagem produzida por artistas viajantes, devemos considerar vários aspectos, tais como a formação do artista viajante, a forma como ele produziu seu trabalho e as possibilidades técnicas com as quais podia contar, as influências estéticas européias, bem como outras influências, que podiam ser científicas ou morais. Louis Choris optou por um tipo de representação artística da ilha de Santa Catarina e de seus habitantes. Sua escolha priorizou a representação da natureza, com seus tipos específicos que melhor representavam a flora e a fauna da região. Mas, ao mesmo tempo, seus trabalhos reproduzem, de forma marginal em algumas das imagens e no centro das atenções noutras, os tipos humanos que viviam na região. Esses foram representados de forma estereotipada, reforçando uma imagem já existente na Europa. O viajante empreendia sua viagem por regiões desconhecidas portando uma postura ambígua: êxtase diante da beleza e do diferente e temor quanto ao desconhecido e aos perigos que iria enfrentar. Esses sentimentos confluem para formar experiências mentais que influenciam de certa forma o olhar, uma vez que este sentido não é mecânico, objetivo, mas subjetivo e fluido. Plínio, autor grego, já chamava a atenção para essa característica do olhar: "a mente é 
o verdadeiro instrumento da visão e da observação, os olhos funcionam como uma espécie de veículo, que recebe e transmite a porção visível da consciência”. ${ }^{31}$ Desse modo, para analisarmos uma imagem, seja ela uma pintura, uma fotografia, ou um filme, não podemos nos ater somente ao que estamos vendo, ao que estamos enxergando. Precisamos analisar o momento de produção dessa imagem, as influências sofridas pelo artista, os interesses estéticos do período, as possibilidades técnicas disponíveis e também o público para quem o produto artístico era direcionado. Em resumo, não podemos considerar a obra como isolada do contexto em que ela foi produzida.

\section{NOTAS}

${ }^{1}$ As discussões presentes neste artigo foram desenvolvidas em minha tese de doutorado: $A$ Lupa e o Diário: História Natural, viagens científicas e relatos sobre a Capitania de Santa Catarina (1763-1822). Porto Alegre: Universidade Federal do Rio Grande do Sul, 2005.

${ }^{2}$ A existência de duas datas deve-se, provavelmente, ao fato de o Império Russo, onde nasceu Choris, utilizar o calendário Juliano e não o Gregoriano, como no Ocidente. O primeiro tem um atraso de 13 dias em relação ao segundo, e seu uso se manteve até janeiro de 1918.

${ }^{3}$ TAUNAY, A. d'E. Cinco peças da velha Iconografia Catarinense. In: Anais do Primeiro Congresso de História Catarinense. Florianópolis: Imprensa Oficial, 1950. v.II, p.124-39.

${ }^{4}$ CHENET, F. L'artiste chargé de mission. Le rôle de l'artiste dans quelques missions scientifiques. In: MOUREAU, F. (Org.) L'oeil aux aguets ou l'artiste en voyage. Paris: Klincksieck, 1995, p.136-7.

${ }^{5}$ FREITAS, M. V. de. Charles Frederick Hartt, um naturalista no Império de Pedro II. Belo Horizonte: Ed. UFMG, 2002, p.120-4.

${ }^{6}$ Segundo Michel de Certeau "as pinturas medievais ou renascentistas representavam a cidade vista em perspectiva por um olho que no entanto jamais existira até então. Elas inventavam ao mesmo tempo a visão do alto da cidade e o panorama que ela possibilitava. Essa ficção já transformava o espectador medieval em olho celeste". CERTEAU, M. de. A Invenção do Cotidiano: 1. Artes de fazer. Trad.: Ephraim Ferreira Alves. Petrópolis: Vozes, 1996, p.170.

${ }^{7}$ MARX, M. Olhando de cima e de frente. Revista USP, São Paulo, n.1, p.173-4 (mar./maio 1989).

${ }^{8}$ SALGUEIRO, V. Vistas urbanas nos álbuns ilustrados por viajantes europeus do século XIX. Tempo, Rio de Janeiro, v.4, p.103, 1997.

${ }^{9}$ PINAULT, M. Le peintre et l'histoire naturelle. Paris: Flammarion, 1990, p.10. 
${ }^{10}$ SALGUEIRO, V., op. cit., p.109.

11 "Dentre estes lugares-comuns destaca-se a divisão tripartite do espaço pictórico, convenção herdada da arte de paisagem do norte europeu, com suas distâncias bem marcadas em planos - plano da frente, plano do meio, plano do fundo - , cujo primeiro plano foram abordados os aspectos de singularidade e localidade também de nossas paisagens, esquema figurativo que tão bem serviu ao sentido cênico da paisagem do viajante." SALGUEIRO, V., op. cit., p.116.

${ }^{12}$ GOMES, E. T. A. Natureza e cultura: representações na paisagem. In: ROSENDAHL, Z; CORRÊA, R. L. Paisagem, imaginário e espaço. Rio de Janeiro: Ed. UERJ, 2001, p.66.

${ }^{13}$ SAUER, C. O. A morfologia da paisagem. In: ROSENDAHL, Z.; CORRÊA, R. L. Paisagem, tempo e cultura. Rio de Janeiro: Ed. UERJ, 1998, p.23-4. Para entender melhor as discussões correntes entre os estudiosos da geografia sobre paisagem, ver as coletâneas organizadas por ROSENDAHL, Z.; CORRÊA, R. L. Paisagem, tempo e cultura e Paisagem, imaginário e espaço. Foram publicados em vários volumes pela Editora da UERJ, nos anos de 1998 e 2001, respectivamente.

${ }^{14}$ GOMES, E. T. A., op. cit., p.56.

${ }^{15}$ Optamos por manter a numeração original do álbum, feita em números romanos. A prancha I retrata uma cena que se passa no convés do barco.

${ }^{16}$ CHORIS, L., op. cit., p.245.

${ }^{17}$ Salomon Gessner .foi escritor, desenhista, pintor e editor de Zurique. Contribuiu para a redescoberta da natureza, combinando tradição bucólica literária ao modo de sentir moderno, à sensibilidade do século XVIII que valorizava a fraternidade, a solidariedade e o desejo de harmonia. Ver: www.letras.up.pt/upi/ilc/vilasboas6.pdf, acesso em: 18.11. 2004.

${ }^{18}$ PINAULT, M., op. cit., p.245-6.

${ }^{19}$ KURY, L. Os três reinos da natureza. In: MARTINS, C. (Org.) O Brasil redescoberto. Rio de Janeiro: Paço Imperial/Minc IPHAN, set./nov. 1999, p.30.

${ }^{20}$ CHORIS, L., op. cit., p.246.

${ }^{21}$ Ibidem, p.246.

${ }^{22}$ As pranchas 69 e 70 estão com as legendas erradas. Por isso não sabemos qual foi a denominação dada por Debret ou pela editora que as publicou. Escolhemos esse nome por ser o que melhor descreve a imagem reproduzida.

${ }^{23}$ Debret produziu sua vista de Desterro entre os anos de 1819 e 1826 . Choris produziu entre os anos de 1815, quando esteve na região Sul do Brasil, e 1822, quando foi publicado o trabalho onde estão reproduzidas as pranchas.

${ }^{24}$ CHORIS, L., op. cit., p.244. 
${ }^{25}$ BELLUZZO, A. M. de M. O Brasil dos Viajantes. v.3: A construção da paisagem. São Paulo: Metalivros; Salvador: Fundação Emílio Odebrecht, 1994, p.83.

${ }^{26}$ Viagem Pitoresca e Histórica ao Brasil reproduz várias das imagens produzidas pelo artista. Foi publicada numa edição de luxo, sob os auspícios de Raimundo Castro Maya, detentor dos direitos de reprodução de seus desenhos, litografias e aquarelas. Nessa obra estão reproduzidas as imagens referentes à Capitania de Santa Catarina, que foram produzidas, provavelmente, entre os anos de 1819 e 1826. Uma cópia dessa edição encontra-se na Seção de Obras Raras da Biblioteca Pública Estadual de Santa Catarina, em Florianópolis. Ver: DEBRET, J. B. Viagem Pitoresca e Histórica ao Brasil. Paris: R. de Castro Maya, 1954.

${ }^{27}$ PANOFSKY, E. Significado nas artes visuais. Trad.: Maria Clara F. Kneese e J. Guinsburg. 1.ed. 1955. São Paulo: Perspectiva, 1991, p.47.

${ }^{28}$ Ibidem. p.53.

${ }^{29}$ GOMBRICH, E. H. Arte e ilusão: um estudo da psicologia da representação pictórica. Trad.: Raul de Sá Barbosa. 1.ed. 1959. São Paulo: Martins Fontes, 1995, p.26.

${ }^{30}$ MENESES, U. T. B. de. Morfologia das cidades brasileiras. Introdução ao estudo histórico da iconografia urbana. Revista USP, São Paulo, n.1, p.152-3 (mar./mai. 1989).

${ }^{31}$ Plínio apud PANOFSKY, E., op. cit., p.15. 